\title{
Alcohol Use and Gastrointestinal Cancer Risk
}

\author{
Hans Scherübl \\ Klinik für Innere Medizin II, Gastroenterologie, GI Onkologie und Infektiologie, Klinikum Am Urban, Vivantes \\ Netzwerk für Gesundheit, Berlin, Germany
}

\section{Keywords \\ Alcohol · Cholangiocarcinoma - Colorectal cancer . Oesophageal cancer · Gastric cancer · Hepatocellular carcinoma $\cdot$ Pancreatic ductal adenocarcinoma}

\section{Abstract}

Background: Alcohol use is an important and potentially modifiable risk factor for gastrointestinal cancers. The more and the longer a person drinks, the higher the risk of cancer becomes. Even modest use of alcohol may increase cancer risk; $100 \mathrm{~g}$ of alcohol per week or less is currently considered to be the limit of low-risk use. Gastrointestinal Cancer Risk: Alcohol is causally associated with oesophageal squamous cell cancer, gastric cancer, hepatocellular carcinoma, colorectal cancer, and most likely also with pancreatic cancer. Alcohol when combined with tobacco smoking or excess body weight can act synergistically to cause gastrointestinal cancer. Exposure to alcohol may have contributed to the recent incidence increases of early-onset gastrointestinal cancers in some Western countries. Conclusions: People with longterm risky alcohol use should be encouraged to join cancer screening programmes. Alcohol cessation appears to be effective in reducing the alcohol-induced, increased cancer risk.

(c) 2020 The Author(s)

Published by S. Karger AG, Basel
\end{abstract}

\section{Introduction}

Alcohol use is a significant and potentially modifiable risk factor for several gastrointestinal cancers. The importance of alcohol as a contributing factor to the gastrointestinal cancer burden is generally underappreciated [1-3]. Addressing high-risk alcohol use is one strategy to reduce the burden of gastrointestinal cancer. Alcohol intake is causally associated with oropharyngeal and larynx cancer, oesophageal (squamous cell) and gastric cancer, hepatocellular carcinoma, breast cancer, colorectal carcinoma (CRC), and most likely also with pancreatic cancer [3-4]. The list of alcohol-associated cancers is still growing. Even modest use of alcohol may increase cancer risk, in particular when combined with either tobacco smoking or excess body weight [5-8].

The threshold of alcohol use for the lowest risk of allcause mortality has recently been lowered to about $100 \mathrm{~g} /$ week for high-income countries [9]. For cardiovascular disease subtypes other than myocardial infarction, there are no risk thresholds below which lower alcohol consumption stops being associated with lower disease risk [10]. 


\section{Alcohol-Mediated Carcinogenesis}

The International Agency for Research on Cancer (IARC) has concluded that acetaldehyde derived from alcoholic beverages is a group 1 carcinogen to humans. This IARC conclusion is based on gene-epidemiologic findings on ALDH2-deficient alcohol drinkers and concerns especially alcohol-related upper digestive tract cancers [1, $2,11,12]$. The WHO stated that alcohol caused more than 3 million deaths each year (5.3\% of all deaths worldwide), and that about $13 \%$ of those were due to cancers [13]. The main component of alcoholic drinks is ethanol. Once ingested, alcohol (ethanol) is metabolized by alcohol dehydrogenase $(\mathrm{ADH})$ into acetaldehyde, which by aldehyde dehydrogenase (ALDH) is then oxidized to acetate $[14,15]$.

Acetaldehyde exerts permanent damage on DNA strands, inhibits DNA repair mechanisms, and shortens telomere length [14-16]. Alcohol promotes ROS generation and impairs the function of scavenger systems, thereby promoting oxidative stress and contributing to genetic instability [14-16]. The microbiome plays an important role as a link between alcohol use and gastrointestinal carcinogenesis $[3,14,15]$.

\section{Genetic Susceptibility}

There is no clinical evidence that the ethanol molecule in itself is genotoxic or mutagenic.

ALDH: evidence has accumulated for genetic susceptibility to the carcinogenic effect of alcohol. There are mutations of the ALDH enzyme. The mutated ALDH2-2 allele codes for an inactive form of ALDH. People with a mutated ALDH2-2 allele accumulate acetaldehyde and, if they ingest alcohol, they are exposed to a much higher risk of alcohol-mediated cancers than people with a wildtype allele. ALDH2-2 mutations occur commonly in (East) Asian countries $[5,17]$. In Japan for example, up to $40 \%$ of the population are heterogenous for the ALDH2 gene and are therefore at a higher risk of alcohol-related upper digestive tract cancers [18]. About 36\% of East Asians (Japanese, Chinese, and Koreans) exhibit a characteristic physiological response to alcohol drinking which includes facial flushing, nausea, and tachycardia. This so-called alcohol flushing response (synonyms: "Asian flush" or "Asian glow") is predominantly due to an inherited ALDH2 deficiency.

$\mathrm{ADH}$ : the allele $\mathrm{ADH}_{1} \mathrm{C}^{*} 1$, a polymorphism of $\mathrm{AD}$ $\mathrm{H} 1 \mathrm{C}$, codes for an enzyme with high capacity to generate acetaldehyde. Thus, the genotype $\mathrm{ADH}_{1} \mathrm{C}^{*} 1 / 1$ is an independent risk factor for alcohol-mediated cancers in drinkers. People with the latter genotype have a genetic predisposition for alcohol-associated cancers [17, 19]. In the study by Homann et al. [19], high-risk alcohol drinkers homozygous for $\mathrm{ADH}_{1} \mathrm{C}^{*} 1$ had a significantly higher risk for developing cancers of the oral cavity, oropharynx, hypopharynx, larynx, and oesophagus, most likely due to higher salivary acetaldehyde levels. Furthermore, individuals who are homozygotes for the genotype $\mathrm{AD}$ $\mathrm{H}_{1} \mathrm{C}^{*} 1 / 1$ are at a particularly high risk of CRC if they drink more than $30 \mathrm{~g}$ of alcohol a day [20]. Based on these genetic studies it is very likely that acetaldehyde generated by bacteria in the colon from ethanol, which has the same concentration as in the blood, may at least in part be responsible for alcohol-associated, colorectal carcinogenesis.

\section{Oral and Oesophageal Microbiome and Acetaldehyde} Production

Poor oral health is a risk factor for oral and oesophageal carcinogenesis. The resident microbiome plays a key role in exposure of the upper digestive tract mucosa to acetaldehyde. Oral dysbiotic microbiome leads to increased growth of opportunistic pathogens (such as Candida yeasts) and may cause an up to $100 \%$ increase in the local acetaldehyde production, which is further modified by organ-specific expression and gene polymorphisms of ethanol-metabolizing and acetaldehyde-metabolizing enzymes. The oropharynx forms a continuity with the oesophagus and stomach via saliva and oral microbes, which both play an essential role in the pathogenesis of alcoholrelated upper digestive tract cancers. A point mutation in the ALDH2 gene has randomized millions of alcohol consumers to markedly increased local acetaldehyde exposure via saliva and gastric juice, leading to a manifold increased risk for upper digestive tract cancers.

Due to a single point mutation in the ALDH2 gene the oropharynx provides a unique gene-epidemiologic and gene-biochemical human cancer model for long-term local acetaldehyde exposure. The model conclusively proves the causal role of local acetaldehyde not only in alcoholrelated oropharyngeal but also in oesophageal and gastric cancer [11]. Regarding this gene mutation-based model, it is important to note that homozygotic ALDH2-deficient persons (with zero ALDH2 activity) are generally not able to drink alcohol at all because of severe "Antabuslike" flushing and other unpleasant reactions. On the other hand, many heterozygotic ALDH2-deficient persons (with some ALDH2 activity) are alcohol consumers or even heavy drinkers or alcoholics. If that is the case, they have dose-dependent increased risks of oropharyngeal, oesophageal, and gastric cancer. When they ingest ethanol, they have 2 -fold higher acetaldehyde levels in saliva and 5 times higher acetaldehyde levels in gastric juice [12]. The cumulative, alcohol-associated cancer risk per standard drink/day (12 g of ethanol/day) is highest in oropharyngeal cancer. At best, a person would never consume tobacco, alcohol, or both. However, even smoking cessation and moderation of alcohol consumption are as- 


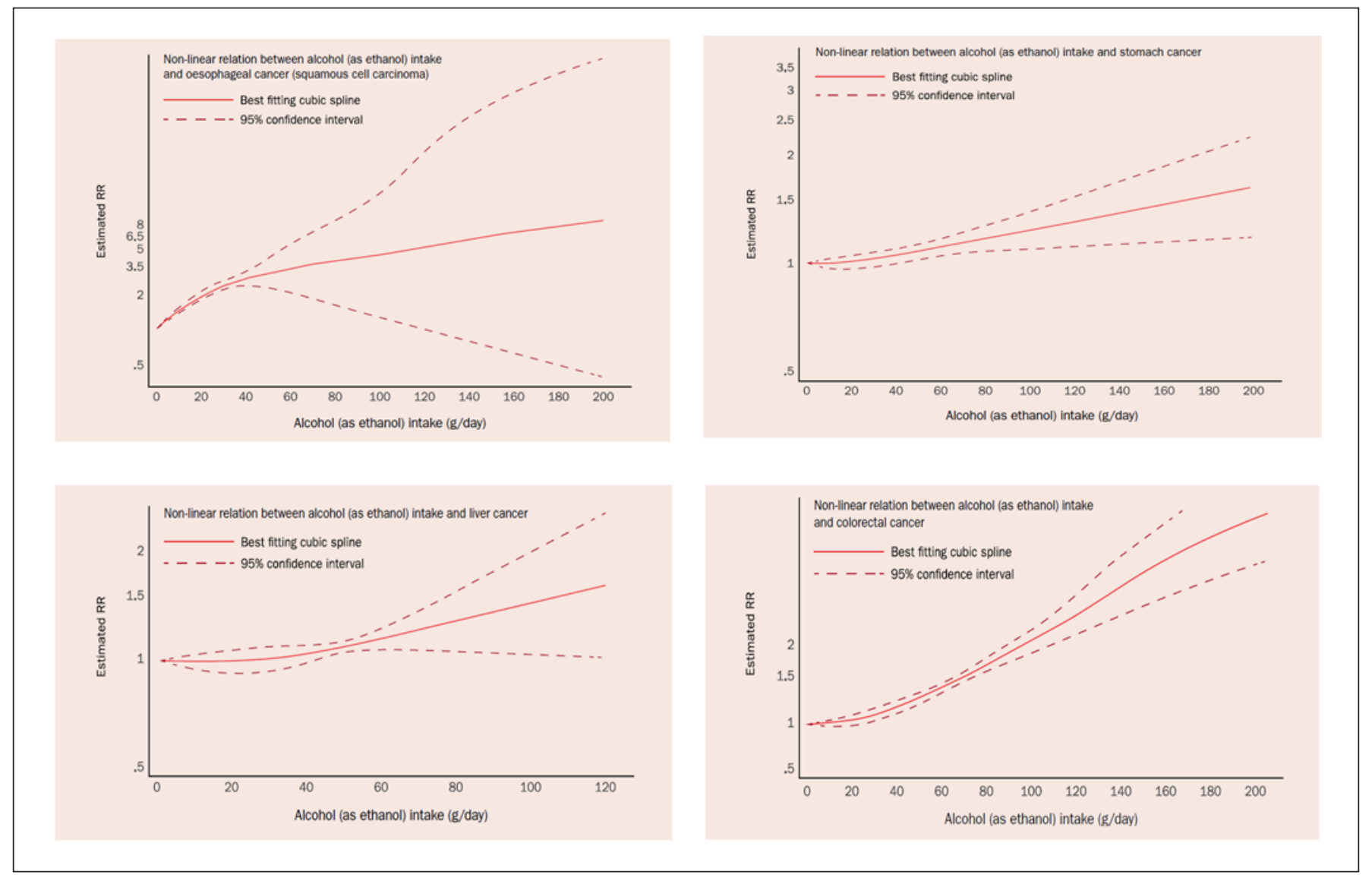

Fig. 1. Non-linear dose-response associations between alcohol intake and risks of oesophageal (squamous cell), gastric, hepatocellular, and colorectal cancers. This material has been reproduced from the World Cancer Research Fund/American Institute for Cancer Research [4] (with permission).

sociated with a marked decrease in local acetaldehyde exposure and alcohol-related cancer risk, especially among established risk groups [12].

\section{Colorectal Cancer}

There is a non-linear dose-response association between alcohol use and CRC risk (see Fig. 1) [4]. The World Cancer Research Fund/American Institute for Cancer Research (WCRF/AICR) report on alcohol and risk of cancer concluded in 2018 that starting from a consumption of $30 \mathrm{~g}$ daily the risk of CRC increased by $7 \%$ for every additional $10 \mathrm{~g}$ in daily alcohol intake [4].

Recent reports show that the incidence of CRC is increasing in a stepwise manner in successively younger birth cohorts both in the USA and Europe [21, 22]. Todays' 20- to 40-year-olds, i.e., young adults, have twice the CRC risk their parents had at the same age. The causes of these recent epidemiological trends are far from clear. Some experts blame our modern sugary diet and excess body weight, while others think that alterations in intestinal microbiota, physical inactivity, and sedentary life- styles may play a role. A possible role of alcohol use in early-onset CRC should also be taken into account [2325]. In the USA the rate of alcohol use disorders has shot up $50 \%$ in the past 10 years - reflecting an $80 \%$ spike for women, according to the most recent National Epidemiologic Survey on Alcohol and Related Conditions [26]. The highest incidence increases were observed in people aged 25-34 years. Among the youngest age group (18-29 years), the prevalence rate of high-risk alcohol drinking was $19 \%$. Similar trends for alcohol use have been reported in some other countries. In the UK, consumption of cider, wine, and spirits increased by $150-400 \%$ over a 30 year time period from 1980 to 2013 [27]. Need of action has been consented.

\section{Alcohol Use and Excess Body Weight}

In several Western countries, more than half of the adult population and about a third of adolescents are affected by excess body weight. Alcohol drinking and obesity may interact additively or even synergistically to cause CRC [7]. With both risk factors being present concurrently already at a young age, their combined carcinogenic actions may contribute to early-onset CRC in young 


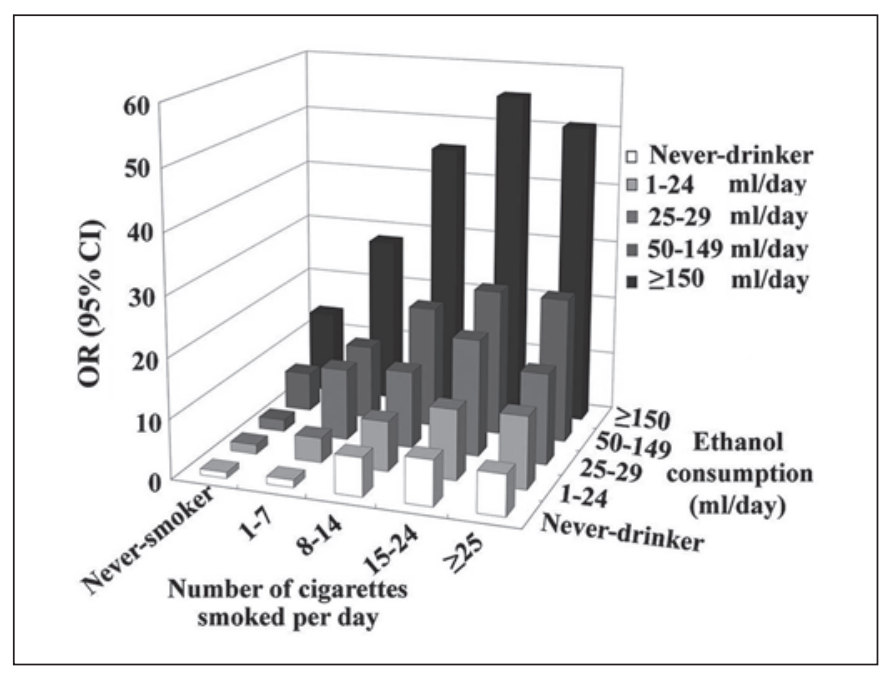

Fig. 2. Combined exposure to alcohol use and cigarette smoking and risk of developing oesophageal squamous cell cancer. Alcohol (ethanol) consumption is given in millilitres of pure alcohol used per day. OR, odds ratio; CI, confidence interval. The material has been reproduced from Peng et al. [5] (with permission).

adults. If alcohol consumption was completely abolished in a theoretical scenario - CRC would be the neoplasm with the second highest absolute number of cancers prevented.

CRC is one of the few cancer diseases in which screening yields impressively great benefits. Screening colonoscopy can either prevent CRC by removing colorectal adenomas or detect CRC at such an early stage in most CRC patients being screened that cure is generally possible. Due to the recent epidemiological changes in early-onset CRC the American Cancer Society released an updated guideline for CRC screening in 2018. The new recommendations say CRC screening should begin at a younger age, i.e., at the age of 45 years for people at average risk [28]. Thus, people with risky alcohol intake are well advised to go for screening colonoscopy at the age of 45 .

\section{Oesophageal Cancer}

Oesophageal cancer is the sixth leading cause of cancer death in the world and is classified into two major histologic types: (o)esophageal squamous cell carcinoma (ESCC) and adenocarcinoma [3]. Consumption of alcoholic drinks is a convincing cause of ESCC. No threshold exists. There is a non-linear dose-response association between alcohol use and ESCC risk (see Fig. 1) [4]. Gene polymorphisms (ALDH2*1*2; ALDH2*2*2; $\mathrm{ADH}^{*} \mathrm{~B}^{*}$; $\mathrm{ADH} 1 \mathrm{C}^{*} 1$ ), tobacco smoking, oral microorganisms, and folate deficiency synergistically enhance the carcinogenic effect of alcohol to induce ESCC [12, 17-19]. Unfortunately, the majority of drinkers are also tobacco smokers
[29]. Epidemiological studies on alcohol use and concomitant smoking have consistently revealed positive, synergistic carcinogenic effects between alcohol intake and tobacco smoking to cause ESCC (see Fig. 2) [5, 17].

In individuals with normally active ALDH2 enzyme (for instance in all Caucasians), blood acetaldehyde levels after ethanol drinking are not elevated. When adequate methodology (no artefactual in vitro acetaldehyde formation from ethanol) is used, blood acetaldehyde levels during ethanol consumption are under the detection limit $(2 \mu \mathrm{M})$. The absolutely highest acetaldehyde levels after alcohol drinking are found in saliva. Instantly after a sip of alcoholic beverage, peak salivary acetaldehyde levels are above $250 \mu \mathrm{M}$, i.e., clearly mutagenic. The instantly elevated acetaldehyde levels in saliva continue for up to $10 \mathrm{~min}$ after each sip. All this acetaldehyde is of microbial origin, i.e., produced from ethanol by several microbial ADH enzymes under aerobic conditions prevailing in the mouth. ALDH2 deficiency results in doubling of long-term acetaldehyde exposure via saliva (i.e., after the distribution phase of alcohol to the whole water phase of the human body). This excess acetaldehyde is most probably derived from salivary glands [11].

Smoking further boosts the high acetaldehyde levels in the saliva [12]. Tobacco smoke contains more than 70 carcinogens and procarcinogens. Ethanol activates cytochrome P4502E1 that metabolizes tobacco procarcinogens to carcinogens. It also decreases retinoic acid to metabolites. A loss of retinoic acid has a negative effect on cell differentiation and thus enhances carcinogenesis [30]. Moreover, ethanol increases cellular membrane permeability and acts as a solvent to facilitate penetration of (pro-)carcinogens into the intracellular domain of mucosal epithelial cells $[5,14,15]$. High-risk alcohol drinkers who smoke should be advised to quit alcohol and tobacco and should consider going for a screening oesophagogastroduodenoscopy. Patients with (previous) head and neck cancers and (previous) alcohol use should be surveilled endoscopically for a second primary ESCC [31].

\section{Gastric Cancer}

At higher levels of alcohol intake (from $45 \mathrm{~g}$ of alcohol per day) there is a non-linear dose-response association between alcohol use and gastric cancer risk (see Fig. 1) [4]. The association is consistent for both cardia and non-cardia gastric cancers. In contrast, most studies reported that light alcohol consumption had no significant effect on gastric cancer [3, 32]. In the EPIC study with 11.4 years of follow-up, the healthiest score of three lifestyle factors (no/little alcohol consumption, no tobacco smoking, and adherence to a Mediterranean diet) was associated with a significant (up to) 50\% decrease in gastric cancer risk [33]. 


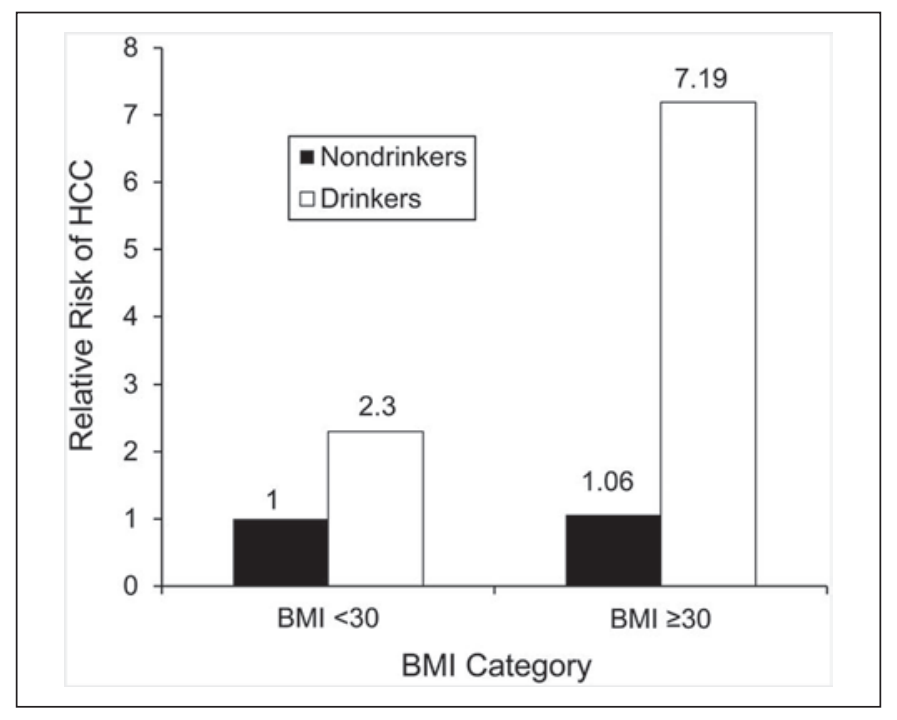

Fig. 3. Synergistic interaction of obesity and alcohol consumption with the risk of hepatocellular carcinoma (HCC). Hazard ratios showing the risk of HCC stratified by extreme obesity and alcohol use status over a mean follow-up of 11.6 years. BMI, body mass index. The material has been reproduced from Loomba et al. [6] (with permission)

The incidence of early-onset cardia cancer is increasing in the USA [21]. (High-risk) alcohol use should be considered as one of the risk factors possibly contributing to this recent epidemiological trend in the USA [34-36]. People with ALDH2 polymorphism are at a higher risk of alcohol-mediated gastric cancer, even with moderate doses of alcohol intake [37]. This is in line with the observation that ingestion of a dose of ethanol by ALDH2-deficient persons results in about 5 times higher acetaldehyde levels in gastric juice compared to that of ALDH2active persons [12].

Moreover, Helicobacter pylori is capable of oxidizing ethanol to acetaldehyde [38]. Important risk factors of gastric cancers comprise $H$. pylori infection, dietary factors (nitroso compounds, high-salt diet with few vegetables), lifestyle factors (tobacco smoking, excess body weight, alcohol use), family history, and atrophic gastritis $[3,4]$. All these risk factors should be taken into account when counselling an individual with risky alcohol intake, regardless of age, to go for a screening esophagogastroduodenoscopy.

\section{Hepatocellular Cancer}

At higher levels of alcohol intake (above about $45 \mathrm{~g}$ of alcohol per day) there is a positive, non-linear dose-response relation between alcohol use and liver cancer (hepatocellular cancer; HCC) risk (see Fig. 1) [4]. The association between ethanol use and HCC may be a direct tox- ic effect, or an indirect one, since alcohol represents an important risk factor for liver cirrhosis, a predisposing condition for HCC. Concomitant alcohol use, diabetes mellitus, and obesity lead to an increased cumulative risk of HCC $[6,39]$. Alcohol intake and obesity interact synergistically to induce HCC (see Fig. 3) [6]. As both excess body weight and alcohol use are very prevalent in adolescents $[26,40]$, (high-risk) alcohol intake when combined with excess body weight may have causally contributed to the increases of (early-onset) HCC in high-income countries [21]. The risk of alcohol-induced HCC can also be modified by the presence of chronic viral hepatitis $(B, C)$, diabetes, or hemochromatosis, resulting in an increased cumulative HCC risk [39, 41, 42]. HCC is a major cause of liver-specific death in patients suffering from liver cirrhosis or non-alcoholic steatohepatitis. Early detection of asymptomatic HCC by liver ultrasound every 6 months should be offered to patients with liver cirrhosis; 6-monthly ultrasound scanning of patients with liver cirrhosis may also detect asymptomatic (early-stage) intrahepatic cholangiocellular carcinoma, a disease which some authors also include in the list of alcohol-associated cancers [43].

\section{Pancreatic Cancer}

The world's deadliest major cancer - pancreatic cancer - still has a 5-year survival rate of about $9 \%$. By 2030 , it is projected to become the second leading cause of cancer-related death in the USA and the (first) leading cause of cancer deaths in the USA by 2050. Well-known risk factors include tobacco smoking, history of diabetes, chronic pancreatitis, excess body weight, $H$. pylori infection, and family history of pancreatic cancer. Alcohol intake is the fourth most important risk factor for pancreatic cancer, with a population-attributable risk of 3\% [44, 45]. At higher levels of alcohol intake (above about $40 \mathrm{~g}$ of alcohol per day) there is (limited) evidence of a nonlinear dose-response relation between alcohol use and pancreatic cancer risk [4].

There are multiplicative interactions between tobacco, alcohol, excess body weight, and diabetes to cause pancreatic cancer. The combination of tobacco smoking and (high-risk) alcohol use appears to lead to an increased cumulative risk of pancreatic cancer $[8,44,46,47]$. The risk for pancreatic cancer may be reduced by $27 \%$ or more by modifying lifestyle risk factors [46, 48]. As alcohol use, tobacco smoking, and excess body weight are prevalent in US adolescents [26, 40], (high-risk) alcohol intake combined with either excess body weight or smoking may have contributed to the recent increases in the incidence of early-onset pancreatic adenocarcinoma [21, 48-50].

In the average population there are to date no effective means available for the early detection of asymptomatic, 
early-stage pancreatic adenocarcinoma. For the time being, primary prevention is the best option to significantly reduce the burden of pancreatic cancer deaths [45-50].

\section{Cancer Prevention: Preventive Oncology}

Alcohol use is not the only potentially modifiable risk factor for gastrointestinal cancers. About $40 \%$ of gastrointestinal cancers may be preventable. In addition to alcohol intake, tobacco smoking, excess body weight, physical inactivity, unhealthy diet, and certain chronic infections are major modifiable risk factors [51]. Thus, clever organized cancer prevention programmes can significantly reduce the burden of gastrointestinal cancer deaths.

\section{Statement of Ethics}

Internationally accepted standards for research practice and reporting were obeyed.

\section{Disclosure Statement}

The author has no conflicts of interest to declare.

\section{References}

1 IARC Working Group. Alcohol drinking. IARC Working Group, Lyon, 13-20 October 1987. IARC Monogr Eval Carcinog Risks Hum. 1988;44:1-378.

2 Baan R, Straif K, Grosse Y, Secretan B, El Ghissassi F, Bouvard V, et al.; WHO International Agency for Research on Cancer Monograph Working Group. Carcinogenicity of alcoholic beverages. Lancet Oncol. 2007 Apr; 8(4):292-3.

3 LoConte NK, Brewster AM, Kaur JS, Merrill JK, Alberg AJ. Alcohol and Cancer: A Statement of the American Society of Clinical Oncology. J Clin Oncol. 2018 Jan;36(1):83-93.

4 World Cancer Research Fund/American Institute for Cancer Research. Continuous Update Project Expert Report 2018. Diet, nutrition, physical activity and cancer: a global perspective. Available from: https://www.wcrf. org/dietandcancer.

5 Peng Q, Chen H, Huo JR. Alcohol consumption and corresponding factors: a novel perspective on the risk factors of esophageal cancer. Oncol Lett. 2016 May;11(5):3231-9.

6 Loomba R, Yang HI, Su J, Brenner D, BarrettConnor E, Iloeje U, et al. Synergism between obesity and alcohol in increasing the risk of hepatocellular carcinoma: a prospective cohort study. Am J Epidemiol. 2013 Feb;177(4): $333-42$.

7 Zhao J, Zhu Y, Wang PP, West R, Buehler S, Sun $Z$, et al. Interaction between alcohol drinking and obesity in relation to colorectal cancer risk: a case-control study in Newfoundland and Labrador, Canada. BMC Public Health. 2012 Feb;12(1):94.

8 Talamini R, Polesel J, Gallus S, Dal Maso L, Zucchetto A, Negri E, et al. Tobacco smoking, alcohol consumption and pancreatic cancer risk: a case-control study in Italy. Eur J Cancer. 2010 Jan;46(2):370-6.

9 Wood AM, Kaptoge S, Butterworth AS, Willeit P, Warnakula S, Bolton T, et al.; Emerging Risk Factors Collaboration/EPIC-CVD/UK Biobank Alcohol Study Group. Risk thresholds for alcohol consumption: combined analysis of individual-participant data for 599912 current drinkers in 83 prospective studies. Lancet. 2018 Apr;391(10129):1513-23.

10 Millwood IY, Walters RG, Mei XW, Guo Y, Yang L, Bian Z, et al.; China Kadoorie Biobank Collaborative Group. Conventional and genetic evidence on alcohol and vascular disease aetiology: a prospective study of 500000 men and women in China. Lancet. 2019 May; 393(10183):1831-42.

11 Lachenmeier DW, Salaspuro M. ALDH2-deficiency as genetic epidemiologic and biochemical model for the carcinogenicity of acetaldehyde. Regul Toxicol Pharmacol. 2017 Jun;86:128-36.

12 Nieminen MT, Salaspuro M. Local acetaldehyde - an essential role in alcohol-related upper gastrointestinal tract carcinogenesis. Cancers (Basel). 2018 Jan;10(1):11.

13 World Health Organization. Alcohol. Available from: https://www.who.int/news-room/ fact-sheets/detail/alcohol.

14 Seitz HK, Stickel F. Molecular mechanisms of alcohol-mediated carcinogenesis. Nat Rev Cancer. 2007 Aug;7(8):599-612.

15 Ratna A, Mandrekar P. Alcohol and cancer: mechanisms and therapies. Biomolecules. 2017 Aug;7(3):61.

16 Harpaz T, Abumock H, Beery E, Edel Y, Lahav M, Rozovski U, et al. The effect of ethanol on telomere dynamics and regulation in human cells. Cells. 2018 Oct;7(10):E169.

17 Cui R, Kamatani Y, Takahashi A, Usami M, Hosono N, Kawaguchi T, et al. Functional variants in ADH1B and ALDH2 coupled with alcohol and smoking synergistically enhance esophageal cancer risk. Gastroenterology. 2009 Nov; 137(5):1768-75.

18 Yokoyama A, Muramatsu T, Ohmori T, Yokoyama T, Okuyama K, Takahashi $\mathrm{H}$, et al. Alcohol-related cancers and aldehyde dehydrogenase-2 in Japanese alcoholics. Carcinogenesis. 1998 Aug;19(8):1383-7.

19 Homann N, Stickel F, König IR, Jacobs A, Junghanns K, Benesova M, et al. Alcohol dehydrogenase $1 \mathrm{C}^{*} 1$ allele is a genetic marker for alcohol-associated cancer in heavy drinkers. Int J Cancer. 2006 Apr;118(8):1998-2002.

20 Homann N, König IR, Marks M, Benesova M, Stickel F, Millonig G, et al. Alcohol and colorectal cancer: the role of alcohol dehydrogenase 1C polymorphism. Alcohol Clin Exp Res. 2009 Mar;33(3):551-6.

21 Sung H, Siegel RL, Rosenberg PS, Jemal A. Emerging cancer trends among young adults in the USA: analysis of a population-based cancer registry. Lancet Public Health. 2019 Mar;4(3):e137-47.
22 Vuik FE, Nieuwenburg SA, Bardou M, Lansdorp-Vogelaar I, Dinis-Ribeiro M, Bento MJ, et al. Increasing incidence of colorectal cancer in young adults in Europe over the last 25 years. Gut. 2019 Oct;68(10):1820-6.

23 Rueda M, Robertson Y, Acott A, Rueda S, Keikhoff A, Guerrero W, et al. Association of tobacco and alcohol use with earlier development of colorectal pathology: should screening guidelines be modified to include these risk factors? Am J Surg. 2012 Dec;204(6):963-7.

24 Rosato V, Bosetti C, Levi F, Polesel J, Zucchetto A, Negri E, et al. Risk factors for youngonset colorectal cancer. Cancer Causes Control. $2013 \mathrm{Feb} ; 24(2): 335-41$.

25 Miguchi M, Hinoi T, Tanakaya K, Yamaguchi T, Furukawa Y, Yoshida T, et al. Alcohol consumption and early-onset risk of colorectal cancer in Japanese patients with Lynch syndrome: a cross-sectional study conducted by the Japanese Society for Cancer of the Colon and Rectum. Surg Today. 2018 Aug;48(8):810-4.

26 Grant BF, Chou SP, Saha TD, Pickering RP, Kerridge BT, Ruan WJ, et al. Prevalence of 12-month alcohol use, high-risk drinking, and DSM-IV alcohol use disorder in the United States, 2001-2002 to 2012-2013: results from the National Epidemiologic Survey on Alcohol and Related Conditions. JAMA Psychiatry. 2017 Sep;74(9):911-23.

27 Williams R, Aspinall R, Bellis M, CampsWalsh G, Cramp M, Dhawan A, et al. Addressing liver disease in the UK: a blueprint for attaining excellence in health care and reducing premature mortality from lifestyle issues of excess consumption of alcohol, obesity, and viral hepatitis. Lancet. 2014 Nov; 384(9958):1953-97.

28 American Cancer Society Updates Colorectal Cancer Screening Guideline. Available from: https://www.cancer.org/latest-news/american-cancer-society-updates-colorectal-cancer-screening-guideline.html.

29 Littleton J, Barron S, Prendergast M, Nixon SJ. Smoking kills (alcoholics)! shouldn't we do something about it? Alcohol Alcohol. 2007 May-Jun;42(3):167-73.

30 Liu C, Russell RM, Seitz HK, Wang XD. Ethanol enhances retinoic acid metabolism into polar metabolites in rat liver via induction of cytochrome P4502E1. Gastroenterology. 2001 Jan;120(1):179-89. 
31 Scherübl H, von Lampe B, Faiss S, Däubler P, Bohlmann P, Plath T, et al. Screening for oesophageal neoplasia in patients with head and neck cancer. Br J Cancer. 2002 Jan;86(2):239_ 43.

32 Rota M, Pelucchi C, Bertuccio P, Matsuo K, Zhang ZF, Ito $\mathrm{H}$, et al. Alcohol consumption and gastric cancer risk-A pooled analysis within the StoP project consortium. Int J Cancer. 2017 Nov; 141(10):1950-62.

33 Buckland G, Travier N, Huerta JM, Buenode-Mesquita HB, Siersema PD, Skeie G, et al. Healthy lifestyle index and risk of gastric adenocarcinoma in the EPIC cohort study. Int Cancer. 2015 Aug;137(3):598-606.

34 Rodríguez-de-Santiago E, Hernanz N, Marcos-Prieto $\mathrm{H}$ et al. A multicentric Spanish study on the characteristics and survival of gastric adenocarcinoma under the age of 60 Gastroenterol Hepatol. 2019 Dec;42(10):595603.

35 Kim MH, Kim SA, Park CH, Eun CS, Han DS, Kim YS, et al. Alcohol consumption and gastric cancer risk in Korea: a case-control study. Nutr Res Pract. 2019 Oct;13(5):425-33.

36 Choi YJ, Lee DH, Han KD, Kim HS, Yoon H, Shin CM, et al. The relationship between drinking alcohol and esophageal, gastric or colorectal cancer: a nationwide populationbased cohort study of South Korea. PLoS One. 2017 Oct;12(10):e0185778.

37 Matsuo K, Oze I, Hosono S, Ito H, Watanabe $\mathrm{M}$, Ishioka $\mathrm{K}$, et al. The aldehyde dehydrogenase 2 (ALDH2) Glu504Lys polymorphism interacts with alcohol drinking in the risk of stomach cancer. Carcinogenesis. 2013 Jul; 34(7):1510-5.

38 Salmela KS, Roine RP, Höök-Nikanne J, Kosunen TU, Salaspuro M. Acetaldehyde and ethanol production by Helicobacter pylori. Scand J Gastroenterol. 1994 Apr;29(4):309-12.

39 Li X, Wang X, Gao P. Diabetes mellitus and risk of hepatocellular carcinoma. BioMed Res Int. 2017;2017:5202684

40 Sung H, Siegel RL, Torre LA, Pearson-Stuttard J, Islami F, Fedewa SA, et al. Global patterns in excess body weight and the associated cancer burden. CA Cancer J Clin. 2019 Mar; 69(2):88-112.

41 Yu M, Lin C, Liu C. Influence of metabolic risk factors on risk of hepatocellular carcinoma and liver-related death in men with chronic hepatitis B: a large cohort study. Gastroenterology. 2017;153:1006-17.

42 Welzel TM, Graubard BI, Quraishi S, Zeuzem S, Davila JA, El-Serag HB, et al. Populationattributable fractions of risk factors for hepatocellular carcinoma in the United States. Am J Gastroenterol. 2013 Aug;108(8):1314-21.

43 Petrick JL, Yang B, Altekruse SF, Van Dyke AL, Koshiol J, Graubard BI, et al. Risk factors for intrahepatic and extrahepatic cholangiocarcinoma in the United States: a populationbased study in SEER-Medicare. PLoS One. 2017 Oct;12(10):e0186643.

44 Jiao L, Mitrou PN, Reedy J, Graubard BI, Hollenbeck AR, Schatzkin A, et al. A combined healthy lifestyle score and risk of pancreatic cancer in a large cohort study. Arch Intern Med. 2009 Apr;169(8):764-70.
45 Rawla P, Sunkara T, Gaduputi V. Epidemiology of pancreatic cancer: global trends, etiology and risk factors. World J Oncol. 2019 Feb; 10(1):10-27.

46 Korc M, Jeon CY, Edderkaoui M, Pandol SJ, Petrov MS; Consortium for the Study of Chronic Pancreatitis, Diabetes, and Pancreatic Cancer (CPDPC). Tobacco and alcohol as risk factors for pancreatic cancer. Best Pract Res Clin Gastroenterol. 2017 Oct;31(5):529_ 36.

47 Rahman F, Cotterchio M, Cleary SP, Gallinger S. Association between alcohol consumption and pancreatic cancer risk: a casecontrolstudy.PLoSOne.2015;10(4):e0124489.

48 Jacobs EJ, Newton CC, Patel AV, Stevens VL, Islami F, Flanders WD, et al. The association of body mass index with pancreatic cancer: variation by age at body mass index assessment. Am J Epidemiol. 2019 Oct:kwz251.

49 McWilliams RR, Maisonneuve P, Bamlet WR Petersen GM, Li D, Risch HA, et al. Risk factors for early-onset and very-early-onset pancreatic adenocarcinoma: a pancreatic cancer case-control consortium (PanC4) analysis. Pancreas. 2016 Feb;45(2):311-6.

50 Bunduc S, Iacob R, Costache R, Stoica B, Radu C, Gheorghe C. Very early onset pancreatic adenocarcinoma - clinical presentation, risk factors and therapeutic options. Chirurgia (Bucur). 2018 May-Jun;113(3):405-11.

51 Scherübl H. Alkoholkonsum und Krebsrisiko [Alcohol use and cancer]. Dtsch Med Wochenschr. 2019 Sep;144(19): 1354-60. German. 